\title{
openheart Thrombotic complications of COVID-19 may reflect an upregulation of endothelial tissue factor expression that is contingent on activation of endosomal NADPH oxidase
}

\author{
James J DiNicolantonio (D) , ${ }^{1}$ Mark McCarty ${ }^{2}$
}

To cite: DiNicolantonio JJ, McCarty M. Thrombotic complications of COVID-19 may reflect an upregulation of endothelial tissue factor expression that is contingent on activation of endosomal NADPH oxidase. Open Heart 2020;7:e001337. doi:10.1136/ openhrt-2020-001337

Accepted 27 May 2020
(A) Check for updates

(C) Author(s) (or their employer(s)) 2020. Re-use permitted under CC BY-NC. No commercial re-use. See rights and permissions. Published by BMJ.

${ }^{1}$ Department of Preventive Cardiology, Mid America Heart Insitute, Kansas, Kansas, USA ${ }^{2}$ Catalytic Longevity, Encinitas, California, USA

Correspondence to Dr James J DiNicolantonio; jjdinico@@gmail.com

\section{ABSTRACT}

The high rate of thrombotic complications associated with COVID-19 seems likely to reflect viral infection of vascular endothelial cells, which express the ACE2 protein that enables SARS-CoV-2 to invade cells. Various proinflammatory stimuli can promote thrombosis by inducing luminal endothelial expression of tissue factor (TF), which interacts with circulating coagulation factor VII to trigger extrinsic coagulation. The signalling mechanism whereby these stimuli evoke TF expression entails activation of NADPH oxidase, upstream from activation of the NF-kappaB transcription factor that drives the induced transcription of the TF gene. When single-stranded RNA viruses are taken up into cellular endosomes, they stimulate endosomal formation and activation of NADPH oxidase complexes via RNA-responsive toll-like receptor 7 . It is therefore proposed that SARS-CoV-2 infection of endothelial cells evokes the expression of TF which is contingent on endosomal NADPH oxidase activation. If this hypothesis is correct, hydroxychloroquine, spirulina (more specifically, its chromophore phycocyanobilin) and high-dose glycine may have practical potential for mitigating the elevated thrombotic risk associated with COVID-19.

\section{A KEY ROLE FOR ENDOSOMAL NADPH OXIDASE IN} ENDOTHELIAL TISSUE FACTOR EXPRESSION

COVID-19 is associated with a high incidence of thrombotic complications. ${ }^{1}$ Necropsy studies reveal platelet-fibrin plugs in pulmonary arterioles, likely contributing to the hypoxaemia characteristic of advanced infection. ${ }^{2}$ It has been suggested that the thrombotic diathesis associated with COVID-19 reflects an endotheliopathy induced by viral infection of endothelial cells. ${ }^{3-5}$ These cells prominently express the ACE2 plasma membrane protein to which the spike protein of SARS-CoV-2 virions bind, enabling their endosomal incorporation into cells. ${ }^{6}$ The thrombotic complications of COVID-19 infection would be readily explained if SARS-CoV-2 infection of endothelial cells induces luminal expression of tissue factor (TF), which could then interact with circulating coagulation factor VII to trigger a proteolytic cascade culminating in the generation of thrombin and fibrin (extrinsic clotting). TF expression is negligible in healthy non-inflamed endothelial cells, but it can be upregulated at the transcription level by various proinflammatory stimuli that activate the NF-kappaB transcription factor. More specifically, the heterodimers $\mathrm{p} 65 / \mathrm{p} 50$ or p65/c-Rel can bind to a novel 'TF-kappaB' sequence in the promoter of the TF gene, driving its induced expression. ${ }^{8-10}$

Various proinflammatory factors that induce $\mathrm{TF}$ in endothelial cells-including tumour necrosis factor-alpha (TNF $\alpha$ ), antiphospholipid antibodies (aPL), ultrafine pollutant particles and homocysteine-have been shown to do so via signalling pathways in which activation of NADPH oxidase complexes plays an obligate role. ${ }^{11-14}$ The effects of aPL and of $\mathrm{TNF} \alpha$ in this regard hinge on the activation of NADPH oxidase in endosomes which has incorporated these agonists. ${ }^{12}$

Prior to the emergence of SARS-CoV-2, it was demonstrated that a number of RNA viruses can activate endosomal NADPH oxidase through a mechanism dependent on toll-like receptor 7 (TLR7), which is activated by binding to single-stranded RNA. ${ }^{15}$ Presumably, these viruses, after binding to cellular plasma membranes, are incorporated into endosomes, and viral RNA released from the virions can interact with endosomal TLR7, triggering NADPH oxidase activation. Indeed, To and colleagues found that eight different types of single-stranded RNA viruses activated endosomal NADPH oxidase in alveolar macrophages, and the two types that did not activate it do not employ endosomes as their primary entry mechanism. ${ }^{15}$ Moreover, this effect was 
absent in alveolar macrophages in which TLR7 expression was knocked out.

SARS-CoV-2 is likewise a single-stranded RNA virus, the intracellular uptake of which is mediated by endosomes. ${ }^{16}$ We postulated that SARS-CoV-2, after incorporation into endosomes within endothelial cells, can likewise activate endosomal NADPH oxidase via TLR7, and that the resulting local production of superoxide/hydrogen peroxide leads to activation of NF-kappaB-by a mechanism yet to be determined-and subsequently to increased expression of TF. At present, while it is difficult to trace clinical studies that have measured serum markers of oxidative stress in COVID-19 patients, the fact that clinical outcomes were poorer in those provinces of China where soil selenium is deficient is compatible with the view that oxidant stress plays a key pathogenic role in this syndrome, and selenium is required for function of multiple antioxidant enzymes, including glutathione peroxidases and thioredoxin reductases. ${ }^{1718}$ Moreover, oxidative stress is a key feature of other viral diseases that evoke acute respiratory distress syndrome and cytokine storm. ${ }^{19}$

\section{THERAPEUTIC IMPLICATIONS OF THE HYPOTHESIS}

This hypothesis is of practical significance because practical measures for inhibiting endosomal NADPH activity may be at hand. Hydroxychloroquine (HCQ), the antimalarial agent now commonly used to treat systemic lupus erythematosus (SLE) and rheumatoid arthritis, has been shown to decrease the elevated risk for thrombotic complications associated with SLE. ${ }^{2021}$ It has recently been demonstrated that HCQ, likely via its alkalinising effect on endosomes, abrogates the ability of aPL to activate endosomal NOX2dependent NADPH oxidase activity, and this reflects a failure of NOX2 to be translocated into endosomes. ${ }^{22}$ The authors further demonstrated that HCQ treatment protects mice from aPL-induced thrombosis. We postulated that HCQ can likewise prevent endosomal NADPH oxidase activation in SARS-CoV-2-exposed endothelial cells, thereby reducing risk for the thrombotic complications associated with COVID-19 infection. This is of particular interest in light of the ability of HCQ to inhibit SARS-CoV-2 in vitro, and of preliminary evidence that administration of HCQ early in the course of COVID-19 may improve therapeutic outcomes, likely by slowing cell-to-cell spread of the virus. ${ }^{23-25}$ HCQ-mediated alkalination of endosomes could be expected to suppress the proteolytic activity of cathepsin $\mathrm{L}$, required for endosomally entrapped SARS-CoV-2 virions to escape into the cytoplasm. ${ }^{162627}$

In addition, phycocyanobilin (PCB), a biliverdin metabolite prominently expressed as a light-absorbing chromophore in cyanobacteria (such as spirulina) and many blue-green algae, has been found to mimic the ability of its chemical relative unconjugated bilirubin to inhibit NADPH oxidase complexes. ${ }^{28}{ }^{29}$ This likely explains the strong antioxidant/anti-inflammatory effects of orally administered spirulina (or of phycocyanin, the spirulina protein to which PCB is covalently attached) in a number of rodent models of heath disorders in which NADPH oxidase activation plays a pathogenic role. ${ }^{28}{ }^{30}$ It is therefore proposed that oral administration of PCB (or of spirulina or of phycocyanin) could help prevent thrombotic complications of COVID-19. Independent considerations suggested that this agent might also be useful for boosting the type 1 interferon response to SARS-CoV-2 and other RNA viruses and for blunting the cytokine storm that complicates late-stage COVID-19. ${ }^{31}$

Theoretical considerations suggested that elevated plasma levels of the amino acid glycine-which is known to have intriguing anti-inflammatory properties-may suppress endosomal activation of NADPH oxidase in cells that express strychnine-inhibitable glycine receptors. ${ }^{32}$ Indeed, endothelial cells express such receptors. ${ }^{33} 34$ Hence, the impact of supplemental glycine-inexpensive, well-tolerated and pleasantly sweet-on TF expression in endothelial cells exposed to proinflammatory stimuli-including SARS-CoV-2-would be of interest to study. Glycine supplementation might also aid control of thrombotic complications via a direct antiaggregatory effect on platelets mediated by glycine receptors. ${ }^{35}$

The upregulatory impact of NADPH oxidase activity on NF-kappaB activation and TF expression is likely mediated by reversible oxidation by hydrogen peroxide of sulfhydryl groups in specific proteins that participate in this activation. ${ }^{36}{ }^{37}$ If so, then boosting synthesis of glutathione and thioredoxin while upregulating the expression of enzymes that work with them to reverse cysteine oxidations (eg, glutathione reductase and thioredoxin reductase) would be expected to counteract the impact of hydrogen peroxide on NF-kappaB activation. ${ }^{38}$ Moreover, increasing the expression of glutathione peroxidase would also counteract the signalling impacts of hydrogen peroxide. These benefits could be achieved with clinically useful phase 2 inducer nutraceuticals-such as lipoic acid, ferulic acid or sulforaphane-complemented by supplementation with $\mathrm{N}$-acetylcysteine; the latter supplies cysteine, the rate-limiting substrate for glutathione synthesis. ${ }^{39-46}$ Glycine supplementation can also promote glutathione synthesis. ${ }^{478}$

A number of studies have observed that nitric oxide (NO) and endothelial NO synthase (eNOS) activity oppose the endothelial induction of TF by various proinflammatory stimuli. The ability of drugs that stimulate or activate soluble guanylate cyclase (sGC) to replicate this effect suggests that cGMP is the downstream mediator of NO's impact in this regard. ${ }^{49}$ Intriguingly, these drugs do not influence the ability of TNF $\alpha$ to suppress protein levels of IkappaB, but nonetheless they do suppress the transcriptional activity of NF-kappaB as assessed with a transfected reporter gene. ${ }^{49}$ Since the oxidative stress induced by NADPH oxidase activation would seem likely to promote uncoupling of eNOS, agents that correct this uncoupling might be expected to downregulate COVID-19-mediated TF induction. Specifically, supplemental intakes of citrulline and of high-dose folate might be useful in this regard, as these agents counteract the uncoupling induced by asymmetric dimethylarginine and by oxidation of 
tetrahydrobiopterin, respectively. ${ }^{50-53}$ Alternatively, agents that directly stimulate or activate sGC might also be useful for suppressing TF induction; in addition to pharmaceuticals that have this effect, supraphysiological concentrations of biotin can stimulate sGC activity. ${ }^{545}$

Measures that quell endothelial oxidative stress while supporting effective eNOS activity might not only help to control the thrombotic complications of COVID-19, but also be expected to blunt the exuberant influx of neutrophils that promote respiratory distress in this syndrome. Nitric oxide, by both cGMP-dependent and cGMP-independent mechanism, inhibits endothelial expression of adhesion factors for neutrophils whereas oxidants upregulate such expression. ${ }^{56-67}$

Box 1 proposes dose schedules for the drugs/nutraceuticals cited earlier that might have practical potential for reducing the thrombotic risk associated with COVID-19. These suggestions deal with agents that might impact the endothelial activation associated with COVID-19. Evidently, drugs that address overactive coagulation or platelet activation may also have potential for controlling the thrombotic complications of this syndrome; in that regard, many physicians are currently employing heparin injections. ${ }^{68} 69$

\section{LIMITATIONS}

This essay proposes a hypothesis that, in the authors' opinion, is credible and, if true, it should help to explain the common thromboembolic complications of COVID-19, while also suggesting practical measures that could lessen the thrombogenicity of vascular endothelium infected by the virus, or exposed to proinflammatory cytokines released in response to viral infection. It is intended to stimulate preclinical study of interactions between SARS-CoV-2 and vascular endothelial cells which could be useful for affirming or disproving the hypothesis. This hypothesis should not be considered to be proven, and the suggestions it provides regarding drugs or nutraceuticals which might ameliorate vascular dysfunction during COVID-19 should not be considered as prescriptive.

Contributors All authors contributed to the final manuscript.

Box 1 Suggested dose schedules for drugs/nutraceuticals with antithrombotic potential in COVID-19

Hydroxychloroquine-200 mg, 2 times per day

Spirulina $-15 \mathrm{~g}$ (rounded tablespoon), one time per day

Glycine powder- $5 \mathrm{~g}, 2-3$ times per day

Lipoic acid-600 mg, 2-3 times per day

Ferulic acid-500 mg, 2 times per day

Broccoli sprout powder- $5 \mathrm{~g}, 1-2$ times per day (providing 20-40 mg

of sulforaphane)

$\mathrm{N}$-acetylcysteine-600 mg, 2-3 times per day

Citrulline powder-2 g, 2 times per day

Folic acid-40 mg, one time per day

Biotin-10 mg, 2-3 times per day
Funding The authors have not declared a specific grant for this research from any funding agency in the public, commercial or not-for-profit sectors.

Competing interests JJD is Director of Scientific Affairs at AIDP. MM is an owner of a nutraceutical company and co-inventor and co-owner of a US patent covering nutraceutical uses of phycocyanobilin oligopeptides derived from cyanobacteria such as spirulina.

Patient consent for publication Not required.

Provenance and peer review Not commissioned; internally peer reviewed.

Open access This is an open access article distributed in accordance with the Creative Commons Attribution Non Commercial (CC BY-NC 4.0) license, which permits others to distribute, remix, adapt, build upon this work non-commercially, and license their derivative works on different terms, provided the original work is properly cited, appropriate credit is given, any changes made indicated, and the use is non-commercial. See: http://creativecommons.org/licenses/by-nc/4.0/.

ORCID iD

James J DiNicolantonio http://orcid.org/0000-0002-7888-1528

\section{REFERENCES}

1 Helms J, Tacquard C, Severac F, et al. High risk of thrombosis in patients with severe SARS-CoV-2 infection: a multicenter prospective cohort study. Intensive Care Med 2020. doi:10.1007/ s00134-020-06062-x. [Epub ahead of print: 04 May 2020].

2 Carsana L, Sonzogni A, Nasr A. Pulmonary post-mortem findings in a large series of COVID-19 cases from northern Italy. to be determined 2020.

3 Escher R, Breakey N, Lämmle B. Severe COVID-19 infection associated with endothelial activation. Thromb Res 2020;190:62

4 Bikdeli B, Madhavan MV, Jimenez D, et al. COVID-19 and thrombotic or thromboembolic disease: implications for prevention, antithrombotic therapy, and follow-up. J Am Coll Cardiol 2020.

5 Varga Z, Flammer AJ, Steiger P, et al. Endothelial cell infection and endotheliitis in COVID-19. Lancet 2020.

6 Lovren F, Pan Y, Quan A, et al. Angiotensin converting enzyme-2 confers endothelial protection and attenuates atherosclerosis. Am J Physiol Heart Circ Physiol 2008;295:H1377-84.

7 Wan Y, Shang J, Graham R, et al. Receptor recognition by the novel coronavirus from Wuhan: an analysis based on decade-long structural studies of SARS coronavirus. J Virol 2020;94.

8 Mackman N. Regulation of the tissue factor gene. Thromb Haemost 1997;78:747-54.

9 Wang J, Mahmud SA, Bitterman PB, et al. Histone deacetylase inhibitors suppress TF- $\kappa B$-dependent agonist-driven tissue factor expression in endothelial cells and monocytes. J Biol Chem 2007;282:28408-18.

10 YD L, BQ Y, Zheng SX, et al. NF-kappaB transcription factor p50 critically regulates tissue factor in deep vein thrombosis. J Biol Chem 2009;284:4473-83

11 Herkert O, Djordjevic T, Belaiba RS, et al. Insights into the redox control of blood coagulation: role of vascular NADPH oxidasederived reactive oxygen species in the thrombogenic cycle. Antioxid Redox Signal 2004;6:765-76.

12 Prinz N, Clemens N, Canisius A, et al. Endosomal NADPH-oxidase is critical for induction of the tissue factor gene in monocytes and endothelial cells. lessons from the antiphospholipid syndrome. Thromb Haemost 2013;109:525-31.

13 Snow SJ, Cheng W, Wolberg AS, et al. Air pollution upregulates endothelial cell procoagulant activity via ultrafine particle-induced oxidant signaling and tissue factor expression. Toxicol Sci 2014;140:83-93.

14 Korkmaz HI, Hahn NE, Jansen KM, et al. Homocysteine-Induced inverse expression of tissue factor and DPP4 in endothelial cells is related to NADPH oxidase activity. Acta Physiol Hung 2019;106:29-38.

15 EE To, Vlahos R, Luong R, et al. Endosomal NOX2 oxidase exacerbates virus pathogenicity and is a target for antiviral therapy. Nat Commun 2017;8:69.

16 Ou X, Liu Y, Lei X, et al. Characterization of spike glycoprotein of SARS-CoV-2 on virus entry and its immune cross-reactivity with SARS-CoV. Nat Commun 2020;11:1620.

17 Zhang J, Taylor EW, Bennett K, et al. Association between regional selenium status and reported outcome of COVID-19 cases in China. Am J Clin Nutr 2020;379.

18 Allan CB, Lacourciere GM, Stadtman TC. Responsiveness of selenoproteins to dietary selenium. Annu Rev Nutr 1999;19:1-16. 
19 Delgado-Roche L, Mesta F. Oxidative stress as key player in severe acute respiratory syndrome coronavirus (SARS-CoV) infection. Arch Med Res 2020.

20 Kaiser R, Cleveland CM, Criswell LA. Risk and protective factors for thrombosis in systemic lupus erythematosus: results from a large, multi-ethnic cohort. Ann Rheum Dis 2009;68:238-41.

21 Jung $\mathrm{H}$, Bobba R, Su J, et al. The protective effect of antimalaria drugs on thrombovascular events in systemic lupus erythematosus. Arthritis \& Rheumatism 2010;62:863-8.

22 Müller-Calleja N, Manukyan D, Canisius A, et al. Hydroxychloroquine inhibits proinflammatory signalling pathways by targeting endosomal NADPH oxidase. Ann Rheum Dis 2017;76:891-7.

23 Colson P, Rolain J-M, Lagier J-C, et al. Chloroquine and hydroxychloroquine as available weapons to fight COVID-19. Int J Antimicrob Agents 2020;55:105932.

24 Yao X, Ye F, Zhang M, et al. In vitro antiviral activity and projection of optimized dosing design of hydroxychloroquine for the treatment of severe acute respiratory syndrome coronavirus 2 (SARS-CoV-2). Clin Infect Dis 2020;10.

25 Liu J, Cao R, Xu M, et al. Hydroxychloroquine, a less toxic derivative of chloroquine, is effective in inhibiting SARS-CoV-2 infection in vitro. Cell Discov 2020;6:16.

26 Fox RI. Mechanism of action of hydroxychloroquine as an antirheumatic drug. Semin Arthritis Rheum 1993;23:82-91.

27 Dufour E, Dive V, Toma F. Delineation of chicken cathepsin L secondary structure; relationship between $\mathrm{pH}$ dependence activity and helix content. Biochim Biophys Acta 1988;955:58-64.

28 McCarty MF. Clinical Potential of Spirulina as a Source of Phycocyanobilin. J Med Food 2007;10:566-70.

29 Zheng J, Inoguchi T, Sasaki S, et al. Phycocyanin and phycocyanobilin from Spirulina platensis protect against diabetic nephropathy by inhibiting oxidative stress. Am J Physiol Regul Integr Comp Physiol 2013;304:R110-20.

30 Romay C, Gonzalez R, Ledon N, et al. Rimbau V. C-phycocyanin: a biliprotein with antioxidant, anti-inflammatory and neuroprotective effects. Curr Protein Pept Sci 2003;4:207-16.

31 McCarty MF, DiNicolantonio JJ. Nutraceuticals have potential for boosting the type 1 interferon response to RNA viruses including influenza and coronavirus. Prog Cardiovasc Dis 2020.

32 McCarty MF, lloki-Assanga S, Lujan LML, et al. Activated glycine receptors may decrease endosomal NADPH oxidase activity by opposing ClC-3-mediated efflux of chloride from endosomes. Med Hypotheses 2019;123:125-9.

33 Yamashina S, Konno A, Wheeler MD, et al. Endothelial cells contain a glycine-gated chloride channel. Nutr Cancer 2001;40:197-204.

34 Yamashina S, Ikejima K, Rusyn I, et al. Glycine as a potent antiangiogenic nutrient for tumor growth. J Gastroenterol Hepatol 2007;22:S62-4.

35 Schemmer P, Zhong Z, Galli U, et al. Glycine reduces platelet aggregation. Amino Acids 2013;44:925-31.

36 Bindoli A, Rigobello MP. Principles in redox signaling: from chemistry to functional significance. Antioxid Redox Signal 2013:18:1557-93.

$37 \mathrm{CM}$ L, Carroll KS. The redox biochemistry of protein sulfenylation and sulfinylation. J Biol Chem 2013;288:26480-8.

38 Holmgren A, Johansson C, Berndt C, et al. Thiol redox control via thioredoxin and glutaredoxin systems. Biochem Soc Trans 2005;33:1375-7.

39 Tanito M, Masutani H, Kim Y-C, et al. Sulforaphane induces thioredoxin through the antioxidant-responsive element and attenuates retinal light damage in mice. Invest Ophthalmol Vis Sci 2005;46:979-87.

40 Chen Z-H, Saito Y, Yoshida Y, et al. 4-Hydroxynonenal induces adaptive response and enhances PC12 cell tolerance primarily through induction of thioredoxin reductase 1 via activation of Nrf2. J Biol Chem 2005;280:41921-7

41 Thimmulappa RK, Mai KH, Srisuma S, et al. Identification of Nrf2-regulated genes induced by the chemopreventive agent sulforaphane by oligonucleotide microarray. Cancer Res 2002;62:5196-203.

42 Lee J, Jung S-Y, Yang K-J, et al. $\alpha$-Lipoic acid prevents against cisplatin cytotoxicity via activation of the NRF2/HO-1 antioxidant pathway. PLoS One 2019;14:e0226769.

43 ZC M, Hong Q, Wang YG, et al. Ferulic acid induces heme oxygenase-1 via activation of ERK and Nrf2. Drug Discov Ther 2011;5:299-305

44 Richman PG, Meister A. Regulation of gamma-glutamyl-cysteine synthetase by nonallosteric feedback inhibition by glutathione. J Biol Chem 1975;250:1422-6.

45 Yagishita Y, Fahey JW, Dinkova-Kostova AT, et al. Broccoli or sulforaphane: is it the source or dose that matters? Molecules 2019;24:3593
46 Bahadoran Z, Mirmiran P, Hosseinpanah F, et al. Broccoli sprouts powder could improve serum triglyceride and oxidized LDL/LDLcholesterol ratio in type 2 diabetic patients: a randomized doubleblind placebo-controlled clinical trial. Diabetes Res Clin Pract 2012;96:348-54

47 McCarty MF, O'Keefe JH, DiNicolantonio JJ. Dietary glycine is ratelimiting for glutathione synthesis and may have broad potential for health protection. Ochsner J 2018;18:81-7.

48 Sekhar RV, Patel SG, Guthikonda AP, et al. Deficient synthesis of glutathione underlies oxidative stress in aging and can be corrected by dietary cysteine and glycine supplementation. Am J Clin Nutr 2011:94:847-53.

49 Sovershaev MA, Egorina EM, Hansen J-B, et al. Soluble guanylate cyclase agonists inhibit expression and procoagulant activity of tissue factor. Arterioscler Thromb Vasc Biol 2009;29:1578-86.

50 Pope AJ, Karuppiah K, Cardounel AJ. Role of the PRMT-DDAHADMA axis in the regulation of endothelial nitric oxide production. Pharmacological Research 2009;60:461-5.

51 McCarty M. Asymmetric dimethylarginine is a well established mediating risk factor for cardiovascular morbidity and MortalityShould patients with elevated levels be supplemented with citrulline? Health Care 2016;4:40.

52 Siu KL, Miao XN, Cai H. Recoupling of eNOS with folic acid prevents abdominal aortic aneurysm formation in angiotensin II-infused apolipoprotein E null mice. PLoS One 2014;9:e88899.

53 Chalupsky K, Kračun D, Kanchev I, et al. Folic acid promotes recycling of tetrahydrobiopterin and protects against hypoxiainduced pulmonary hypertension by Recoupling endothelial nitric oxide synthase. Antioxid Redox Signal 2015;23:1076-91.

54 Vesely D. Biotin enhances guanylate cyclase activity. Science 1982;216:1329-30

55 Watanabe-Kamiyama M, Kamiyama S, Horiuchi K, et al. Antihypertensive effect of biotin in stroke-prone spontaneously hypertensive rats. Br J Nutr 2008;99:756-63.

56 Takenaka K, Nishimura Y, Nishiuma T, et al. Ventilator-Induced lung injury is reduced in transgenic mice that overexpress endothelial nitric oxide synthase. Am J Physiol Lung Cell Mol Physiol 2006;290:L1078-86.

57 Ware LB, Magarik JA, Wickersham N, et al. Low plasma citrulline levels are associated with acute respiratory distress syndrome in patients with severe sepsis. Crit Care 2013;17:R10.

$58 \mathrm{Li} \mathrm{J}$, Wu F, Zhang H, et al. Insulin inhibits leukocyte-endothelium adherence via an Akt-NO-dependent mechanism in myocardial ischemia/reperfusion. J Mol Cell Cardiol 2009;47:512-9.

59 TL F, Zhang WT, Zhang L, et al. Xu M. L-arginine administration ameliorates serum and pulmonary cytokine response after gut ischemia-reperfusion in immature rats. World $\mathrm{J}$ Gastroenterol 2005;11:1070-2.

60 Ahluwalia A, Foster P, Scotland RS, et al. Antiinflammatory activity of soluble guanylate cyclase: cGMP-dependent down-regulation of $\mathrm{P}$-selectin expression and leukocyte recruitment. Proc Natl Acad Sci U S A 2004;101:1386-91.

61 Wong D, Prameya R, Dorovini-Zis K, et al. Nitric oxide regulates interactions of PMN with human brain microvessel endothelial cells. Biochem Biophys Res Commun 2004;323:142-8.

62 Dal SD, Moreira AP, Freitas A, et al. Nitric oxide inhibits neutrophil migration by a mechanism dependent on ICAM-1: role of soluble guanylate cyclase. Nitric Oxide 2006;15:77-86.

63 Tummala PE, Chen X-L, Medford RM. NF- kappa B independent suppression of endothelial vascular cell adhesion molecule-1 and intercellular adhesion molecule-1 gene expression by inhibition of flavin binding proteins and superoxide production. $J$ Mol Cell Cardiol 2000;32:1499-508.

64 Takano M, Meneshian A, Sheikh E, et al. Rapid upregulation of endothelial $P$-selectin expression via reactive oxygen species generation. Am J Physiol Heart Circ Physiol 2002;283:H2054-61.

65 Yun MR, Kim JJ, Im DS, et al. Involvement of NAD(P)H oxidase in the enhanced expression of cell adhesion molecules in the aorta of diabetic mice. Life Sci 2004;75:2463-72.

66 Vlahos R, Stambas J, Bozinovski S, et al. Inhibition of Nox2 oxidase activity ameliorates influenza A virus-induced lung inflammation. PLoS Pathog 2011;7:e1001271.

67 EE T, Luong R, Diao J, et al. Novel endosomal Nox2 oxidase inhibitor ameliorates pandemic influenza A virus-induced lung inflammation in mice. Respirology 2019;24:1011-7.

68 Lindahl U, Li Jin-Ping. Heparin - an old drug with multiple potential targets in Covid-19 therapy. J Thromb Haemost 2020

69 Testa S, Paoletti O, Giorgi-Pierfranceschi M, et al. Switch from ora anticoagulants to parenteral heparin in SARS-CoV-2 hospitalized patients. Intern Emerg Med 2020:1-3. 